\title{
Vivências subjetivas de familiares que cuidam de idosos dependentes
}

\author{
Subjective life experiences of family caregivers of dependent older \\ adults
}

Denise Machado Duran Gutierrez (https://orcid.org/0000-0002-0031-3045) ${ }^{1}$ Girliani Silva de Sousa (https://orcid.org/0000-0002-0988-5744) ${ }^{2}$

Ana Elisa Bastos Figueiredo (https://orcid.org/0000-0001-7207-0911) ${ }^{3}$

Maria de Nazaré de Souza Ribeiro (https://orcid.org/0000-0002-7641-1004) ${ }^{4}$

Cleisiane Xavier Diniz (https://orcid.org/0000-0003-4689-6204) ${ }^{4}$

Guiomar Alegria Souza Silva Nobre (https://orcid.org/0000-0001-8672-5106) ${ }^{1}$
${ }^{1}$ Faculdade de Psicologia, Universidade Federal de Amazonas. Av. General Rodrigo Octavio Jordão Ramos 1200, Coroado I. 69067-005 Manaus AM Brasil.

ddgutie@ufam.edu.br.

${ }^{2}$ Departamento de

Enfermagem Clínica e Cirúrgica, Escola Paulista de Enfermagem, Universidade Federal de São Paulo. São Paulo SP Brasil.

${ }^{3}$ Departamento de Estudos sobre Violência e Saúde Jorge Careli, Escola Nacional de Saúde Pública, Fiocruz. Rio de Janeiro RJ Brasil. ${ }^{4}$ Escola Superior de Ciências da Saúde, Universidade do Estado do Amazonas. Manaus AM Brasil.
Abstract This study aimed to understand the subjective meanings attributed to home care by family caregivers of dependent older adults through a multicenter qualitative investigation that gathered 84 in-depth interviews with family caregivers from eight Brazilian locations. The hermeneuticdialectic, theoretical, methodological framework was employed. The following categories emerged from the analysis: 1. Movements inhibiting emotions and feelings; 2. Presence of processes of symbiosis and emotional dependence in the older adult-relative relationship; 3. Contentment in caring for the dependent older adult; and 4. Giving up current and future life projects. The results reveal life experiences marked by symbiotic processes, emotional dependence, and psychic stress. Dependence causes suffering and feelings of despair, powerlessness, impatience, but also solidarity and empathy. Withdrawal from the job market, social depreciation of family caregiver's activity, social isolation, neglected self-care, and family conflicts impact caregivers' subjectivity. The elaboration of public policies must consider the social-affective life experiences of family caregivers of dependent older adults in order to include the care of those providing care.

Key words Family caregivers, Dependent older adult, Care, Subjectivity
Resumo O objetivo do presente estudo foi compreender os sentidos subjetivos atribuídos pelos cuidadores familiares de idosos dependentes do cuidado ofertado no domicílio, por meio de uma investigação qualitativa multicêntrica que reúne entrevistas em profundidade com 84 cuidadores familiares em oito localidades no Brasil. Utilizouse o referencial teórico metodológico hermenêutico-dialético. Na leitura das entrevistas emergiram as seguintes categorias que serviram de base para as análises: 1. Movimentos de inibição de emoções e sentimentos; 2 . Presença de processos de simbiose e de dependência emocional na relação entre idoso e familiar; 3. Contentamento em cuidar do idoso dependente; e 4. Renúncia a projetos de vida atuais e futuros. Os resultados apontam vivências marcadas por processos de simbiose, dependência emocional e estresse psíquico. A dependência gera sofrimento e sentimentos de desespero, impotência, impaciência, mas também de solidariedade e empatia. A renúncia ao trabalho profissional, a desvalorização social da atividade de cuidador familiar, o isolamento social, o cuidado "descuidado" de si e os conflitos familiares influenciam a subjetividade dos cuidadores. A formulação de politicas públicas precisa considerar as vivências socioafetivas dos cuidadores familiares de idosos dependentes, para nelas incluir o cuidado de quem cuida.

Palavras-chave Cuidadores familiares, Idoso dependente, Cuidado, Subjetividade, Pesquisa qualitativa 


\section{Introdução}

A longevidade quando acompanhada de perdas cognitivas e perdas funcionais demanda cuidados especiais e permanentes que, geralmente, são prestados no domicílio sob a responsabilidade dos familiares ${ }^{1}$ como é o caso dos idosos dependentes em foco neste artigo.

Essa nova realidade que reorienta a dinâmica familiar e transforma o familiar em cuidador informal pode levá-lo a experimentar vários sentimentos e emoções, quase sempre contraditórios e ambíguos, geralmente marcados por estados depressivos; problemas de saúde física; dificuldades financeiras pela perda ou dificuldade de conciliar o cuidado com o trabalho remunerado; vivências familiares disfuncionais e insegurança na forma de lidar com a pessoa dependente, por despreparo e falta de suporte técnico ${ }^{2,3}$.

Apesar desse contexto interno conflituoso, alguns cuidadores, como veremos neste texto, desejam participar ativamente do cuidado do idoso em domicílio e apreciam quando podem interagir, receber e trocar informações sobre o cuidado com equipes de saúde ou outros profissionais ${ }^{3}$.

Autores $^{4,5}$ apontam que existem realidades culturais diferentes entre os países no acompanhamento e assistência ao cuidador familiar. Em alguns países da América Latina e do Oriente, essa tarefa é vista como intransferível. Portanto, é fundamental considerar como o cuidador familiar vivencia o cuidar do outro, nessa relação intersubjetiva intrinsecamente relacionada ao contexto sociocultural e econômico. Adota-se aqui a perspectiva teórica de González-Rey ${ }^{6}$ que define subjetividade como "um sistema complexo que tem dois espaços de constituição permanente e inter-relacionados: o individual e o social, que se constituem de forma recíproca e, ao mesmo tempo, cada um está constituído pelo outro".

Consideramos que o tema do sujeito cuidador e de sua subjetividade é muito pouco tratado na saúde pública. Definimos então como objetivo desta investigação, compreender e analisar os sentidos subjetivos atribuídos pelos cuidadores familiares de idosos dependentes ao cuidado ofertado no domicílio, aprofundando suas formas de interpretar a experiência de cuidar e circunstâncias multidimensionais que envolvem essa atividade.

\section{Percurso metodológico}

Trata-se de um estudo qualitativo que é parte do Projeto "Estudo situacional de idosos dependentes que residem com suas famílias visando subsidiar uma Política de Atenção e de Apoio aos Cuidadores" realizada em oito municípios brasileiros das cinco regiões do país. O estudo ora em foco, reuniu dados de 84 casos de cuidadores familiares de idosos dependentes: filhas, filhos, esposas, esposos, sobrinhas, netas, noras, ex-noras e ex-esposas. Com o conjunto de seus depoimentos foi possível compor um quadro expressivo das experiências vividas por eles.

Adotou-se a perspectiva teórica hermenêutica-dialética ${ }^{8,9}$ por meio de três movimentos metodológicos: compreender (entender) e interpretar/analisar. Segundo Gadamer ${ }^{10}$ :

Entender e interpretar os textos pertence claramente ao todo da experiência do homem no mundo. Na sua origem, ofenômeno hermenêutico não é, de forma alguma, um problema de método. $O$ que importa a ele, em primeiro lugar, não é estruturação de um conhecimento seguro, que satisfaça aos ideais metodológicos da ciência - embora, sem dúvida, se trate também aqui do conhecimento e da verdade. Ao se compreender não se compreende apenas textos, mas também se reconhecem verdades.

Os cuidadores familiares de idosos dependentes que participaram da investigação foram encaminhados para entrevista pelos profissionais da atenção primária, ambulatórios especializados em geriatria e por indicação de outras famílias. As entrevistas foram semiestruturadas e orientadas por um roteiro que incluía: dados iniciais (naturalidade, etnia/cor, local de residência, parentesco/vínculo, tempo de experiência no cuidado); percepção e sentimentos do cuidador familiar sobre a sua função, sobre si mesmo, seu relacionamento com a pessoa idosa, emoções e influências na vida pessoal. Foram agendadas, gravadas, conforme conveniência dos entrevistados, e realizadas por pesquisadores experientes e treinados, tendo duração média de 60 minutos, com prévia assinatura do Termo de Consentimento Livre e Esclarecido (TCLE) pelos participantes. O projeto foi aprovado pelo Comitê de Ética em Pesquisa da Escola Nacional de Saúde Pública/Fiocruz/RJ.

As entrevistas foram transcritas e analisadas em profundidade, articulando o objetivo da investigação, o relato dos entrevistados, inferências compreensivas - interpretativas dos pesquisadores e discussão dos achados, frente à literatura. 
Destacaram-se os seguintes temas de relevância em relação aos processos de subjetivação dos familiares entrevistados: 1. Movimentos de inibição de emoções e sentimentos; 2. Presença de processos de simbiose e de dependência emocional na relação idoso e familiar; 3. Contentamento em cuidar do idoso dependente; e 4. Renúncia a projetos de vida atuais e futuros.

\section{Resultados e discussão}

Os resultados e as discussões aqui apresentados provêm de uma elaboração hermenêutica, submetida à crítica e às contradições, dos depoimentos de 71 mulheres e 13 homens cuidadores familiares: filhas, filhos, esposas, esposos, ex-esposas e outros membros da família. No entanto, apenas alguns depoimentos são apresentados, dando força às relevâncias dos cuidadores em conjunto. No aprofundamento das falas e situações, foi possível perceber regularidades na experiência subjetiva. Mas há singularidades e questões referentes a grupos específicos. O fato de serem ouvidas pessoas de vários lugares não alterou os resultados, que tendem a se unificar pela força das mesmas situações vividas.

A faixa etária dos cuidadores variou de 30 anos a 88 anos e a renda familiar, de um a dez salários mínimos, incluindo ganhos provenientes do trabalho e aposentadoria do idoso. Os participantes que se dedicam sozinhos e de modo integral ao cuidado não possuem renda pessoal. Os membros familiares cuidam de idosos com diversos graus e áreas de dependência. O tempo que têm de cuidados ao familiar varia de seis meses a dezenove anos.

Os temas de relevância que emergiram dos relatos dos familiares cuidadores estão apresentados a seguir.

\section{Movimentos de inibição de sentimentos e emoções}

As emoções e os sentimentos são movimentos diferentes expressos por um indivíduo em relação ao outro. Para Jung ${ }^{11}$, "nenhuma definição intelectual será capaz de reproduzir, ainda que seja aproximadamente, o que é específico do sentimento" ${ }^{11}$. Mauss ${ }^{12}$ também nos apresenta uma forma de compreender as emoções e sentimentos e como elas se abrigam nos indivíduos:

expressões dos sentimentos do indivíduo e do grupo são mais do que simples manifestações, são sinais, expressões compreendidas, em suma, uma linguagem. A pessoa os manifesta a si mesma por conta dos outros.

Sentimentos e emoções estão relacionados entre si. Assim como uma emoção desperta um sentimento, um sentimento pode mobilizar uma emoção correspondente àquele sentimento, pois a emoção é um conjunto de respostas, substanciada pelas memórias emocionais e surge quando recebemos um estímulo externo. O sentimento é uma resposta à emoção.

O movimento de inibição dos sentimentos e emoções que se busca destacar aqui pode ser visto no relato de VCCS, 34 anos, filha caçula residente em Brasília que cuida da mãe há quatro anos: Não estava preparada para cuidar da minha mãe, e eu me sinto cansada de ter que controlar diariamente as necessidades dela. Não divido minhas angústias, prefiro guardar só para mim, não quero atrelar minhas reclamações a um sentimento de vitimização.

Nesse caso, a inibição das emoções acontece num contexto em que a perda de autonomia da mãe idosa foi sentida pela filha como uma situação desafiadora que deve enfrentar, sem reclamar e se lastimar. Muitos manifestaram os mesmos sentimentos dizendo que precisam ser fortes: não se permitem adoecer; calam-se para não discutir com o idoso; fazem ouvido mouco ao que o idoso diz; evitam provocar irritações; procuram distrair e reorientar o rumo das conversas; relevam os ataques sofridos; permanecem calados frente a situações de tensão.

Quando questionados sobre como se tornaram cuidadores, em geral, as respostas demonstram o inusitado da nova situação que tiveram que assumir, sem dar ouvidos às próprias frustrações e angústias que a partir de então os invadiram ${ }^{13,14}$. A expressão eu tenho que me controlar ao extremo, denuncia a habilidade que desenvolveram de inibir as emoções num contexto de desamparo ou de ausência de reconhecimento e apoio. No entanto, os entrevistados que possuem alternância de cuidado com os outros familiares, ou com cuidadores formais, demonstraram mais liberdade e tempo de expressar afetos e emoções.

Investigações realizadas em Nova Zelândia e no Canadá ressaltam que os cuidadores familiares frequentemente não recebem informações necessárias para se sentirem seguros, especialmente, nos estágios iniciais do cuidado ${ }^{2,3}$. Ora, o fato de desconhecer a condição real de adoecimento do idoso e como atuar frente a ela aumenta a tensão, a insegurança e o medo de falhar na oferta de cuidado.

As conversas com as mulheres demonstraram que, no exercício do cuidado, reproduziam seu 
destino tradicional de gênero: servir, desempenhando o script tradicional no lar, no casamento e na assistência à pessoa idosa enferma até os limites da resistência física e psíquica. Essa realidade, frequentemente encontrada na pesquisa, é comentada também na literatura sobre países como a China, onde à mulher cabe a responsabilidade pelo cuidado ${ }^{5,15}$. Entre as participantes não foi identificada nenhuma cuidadora que tenha sequer comentado ou feito críticas quanto à perspectiva de gênero no exercício do cuidado.

Em nome do trabalho profissional e de tudo que lhes é exigido na cartilha cultural masculina, os homens relataram mais dificuldades no relacionamento com a pessoa idosa, como se observa no relato de EP, 65 anos, filho que cuida da mãe há oito anos em Fortaleza:

Convivência com o idoso é complicado, ela briga por qualquer coisa, me esculhamba, eu relevo porque é minha mãe, tenho muito respeito, mas eu fico abatido, cansado. A gente se entristece com as coisas, eu nem doente posso ficar, estou praticamente esquecido. Eu não estou vivendo...

Esse filho abdicou de seu trabalho e vida pessoal para se dedicar ao cuidado da mãe com Alzheimer, o que o adoece física e psiquicamente. Essa realidade foi recorrente na pesquisa e é relatada na literatura ${ }^{2}$. Entretanto, encontramos também alguns homens jovens, solteiros ou divorciados que conseguem conciliar o cuidado ao idoso com o trabalho remunerado e contam com a ajuda de familiares ou de cuidadores formais. Esses costumam monitorar à distância a pessoa que deixam em seu lugar, até que, pós-trabalho, assumem o cuidado com devoção e delicadeza. Observou-se que alguns homens são capazes de fazer alterações na rotina, dormir ao lado da pessoa idosa, prover-lhe carinho e garantir-lhe segurança, rompendo estereótipos masculinos ${ }^{16,17}$.

Ter cuidadores auxiliares é uma alternativa viável para que homens e mulheres possam exercer sua profissão, mas também para terem tempo para si e se enxergarem no mundo. No entanto, a maioria das famílias, por causa das dificuldades financeiras ou falta de solidariedade, o mais comum é deixar-se o cuidado nas mãos de um familiar apenas.

Filhos e filhas mostram que vergonha e medo também compõem o mosaico de emoções que os cuidadores e cuidadoras vivenciam ${ }^{18,19}$ e que precisam ser inibidas a bem do cuidado. RNM de 41 anos, filho solteiro que mora em Belo Horizonte e cuida da mãe há três anos relata o desconforto que sente ao manipular o corpo da mãe idosa durante os cuidados diários com a higiene:
Eu achei mais difícil foi o banho, tinha medo porque eu não estava acostumado, medo de machucar e ela cair e tinha muita vergonha, mas a gente tem que jogar fora nessa hora e cuidar por que não tem jeito, como que ia ficar? Vai dar bicho em cima da cama? Tem que cuidar!

Esse parece ser um ponto sensível, pois diz respeito à sexualidade e seus tabus, embora, conforme sinaliza $\operatorname{Hogan}^{20}$ :

A sexualidade deve ser compreendida como intrínseca a todo o indivíduo, a qualquer momento de sua vida, considerada singular a cada pessoa. A sexualidade é a fusão de sentimentos simbólicos $e$ físicos, como ternura, respeito, aceitação e prazer. É construída progressivamente, sendo influenciada pela história, pela sociedade e pela cultura, conforme os aspectos individuais e psíquicos de cada um.

Tocar o corpo nu e genitais da mãe ou do pai se insere num importante interdito social. Quando a doença crônica modifica o corpo da pessoa idosa, tornando-o debilitado, ela anuncia sua inevitável temporalidade ${ }^{21}$. O cuidado ganha assim uma forte dimensão de respeito à dignidade do outro ${ }^{2,19}$.

Quando o cuidado é exercido por um dos cônjuges, presenciar a pessoa amada passando por dores e limitações funcionais significa defrontar-se com o próprio desamparo face à finitude da vida, como no relato de FAG, 67 anos, residente em Manaus, marido que cuida da esposa há quatro anos:

Às vezes eu fico pensando como é que seria, por exemplo, agora como estamos aposentados, ninguém ia parar aqui, andando com ela até terminar a vida, deixava os meninos tomando conta da casa e a gente ia viajar. Eu tenho pena dela de noite quando ela fica chorando com dor e eu não posso fazer nada porque a dor é no osso e no osso não tem remédio que passe.

Essa fala de empatia cultivada num casamento de cinquenta anos e mais, revela que doi em mim a dor dela. A perda da saúde e da autonomia passa a fazer parte da história do marido, pois ambos estão envoltos nos mesmos sentimentos de finitude ${ }^{14}$.

\section{Presença de processos de simbiose e de dependência emocional na relação idoso e familiar}

Nessa sessão estão condensados conteúdos que evidenciam processos de simbiose e dependência emocional. A simbiose é caracterizada como uma estreita interdependência entre duas ou mais pessoas que se complementam para se 
manterem controladas e, em certa medida, satisfeitas, as necessidades das partes mais imaturas de suas personalidades ${ }^{22}$. A dependência emocional é definida por quatro componentes: (1) o motivacional que refere à necessidade de suporte, orientação e aprovação; (2) o afetivo, à ansiedade sentida pelo indivíduo diante de situações nas quais necessita agir independentemente; (3) o comportamental alude à tendência de buscar ajuda de outros e de submissão em interações interpessoais; e o (4) cognitivo, remete à autopercepção do sujeito como impotente e ineficaz ${ }^{23}$.

Parte desses processos - simbiose e dependência emocional - são marcados por uma percepção infantilizada do idoso e pela dificuldade de reconhecimento dos limites entre cuidar, promover autonomia e preservar a liberdade do idoso. Esse risco foi relatado por PFEM, residente em Porto Alegre, uma filha de 36 anos que cuida da mãe há 10 meses:

Ver que ela não consegue fazer certas coisas é um pouco triste, decepcionante eu tenho que estar sempre me controlando para eu não querer fazer tudo e deixar ela, com autonomia dela, fazer as coisas dela e isso é um pouco difícil para mim. É uma certa dificuldade que eu tenho para entender que ela tem o tempo dela, o espaço dela e que ela vai fazer no tempo dela.

A situação da dependência pode ser angustiante para os familiares que veem seus entes queridos, de modo progressivo ou abrupto, perderem a autonomia ${ }^{2,19}$. Isso é considerado por alguns como o desafio mais difícil: presenciar com impotência as profundas modificações no corpo e no comportamento do idoso. No entanto, é necessário fugir à tentação da infantilização que pode ter várias consequências; contribuir para o apagamento da história de vida do ente querido, de suas experiências e de suas capacidades intelectuais e cognitivas ${ }^{2}$. A infantilização também aumenta o sentimento de inutilidade no idoso e reforça a simbiose e a dependência emocional entre ele e seu cuidador. São riscos admitidos por entrevistados como o mostra o relato de MPR, 55 anos, residente em Manaus, esposa que cuida do marido há cinco anos:

Eu estava pecando se eu não estivesse ali direto com ele, às vezes você acaba se envolvendo muito e esquece de você mesmo, é como ter um bebê especial em casa e acaba que você não se vê, você só vê ali aquela pessoa e tem medo de desligar e aquela pessoa ter algum piripaque e você se culpar pelo resto da vida porque não estava ali.

Bleger et al. ${ }^{22}$ mostram que a enfermidade da pessoa idosa pode afetar a vida do cuidador fa- miliar quando ele não tem espaço para elaborar seus sentimentos que se manifestam por meio da simbiose entre ambos. Para que esse processo de mútua dependência não se estabeleça, o desejável é alternar a assistência com outros, de forma a conciliar o cuidado com outras interações e ajuda profissional. Tema sobre o qual fala a cuidadora, MPR, residente em Manaus, esposa de 55 anos que cuida do marido com sequela de AVC há cinco anos:

Depois do terceiro ano, a equipe foi ficando mais afinada, eu já confio neles e fui me dar ao luxo de receber alguns convites para tomar cafezinho.

No relato de TMS de 70 anos residente em Araranguá, esposa que cuida do marido há 54 anos, percebemos a manifestação de uma dependência emocional anterior, que tornou a cuidadora muito frágil e sem referência:

Para mim acabou a vida, depois que ele ficou doente porque, quando ele estava bonzinho, ele me levava no médico, ele que ia buscar meus exames, ele que ia marcar, ele que fazia tudo!

A necessidade de ter que assumir o cuidado e inverter a relação passando de pessoa cuidada a cuidadora, faz emergir os problemas de uma estrutura de dependência que já estava presente no cotidiano do casal ${ }^{23}$.

\section{Contentamento em cuidar}

O sentimento de entrega, de reciprocidade, de assistir por gratidão foi encontrado em vários depoimentos de cuidadores que se sentem justos, generosos e felizes no caminho adotado de se entregarem ao que fazem ${ }^{19,24,25}$. É o que percebemos no depoimento de LMAS de 64 anos, residente em Teresina, filha que cuida do pai acamado há um ano, e no de ICP, 38 anos, residente em Manaus, filha que cuida da mãe há três anos, ambos a seguir:

Faço tudo com muita alegria, vejo que hoje estou tendo a oportunidade de dar a meus pais o carinho que me deram quando criança. Sinto isso em cada fralda que troco, cada gole d'água que ofereço. Estou satisfeita e muito feliz, me sinto agradecida de poder retribuir o que um dia eles fizeram comigo e hoje faço para eles.

Eu tenho prazer em cuidar da minha mãe. Ela é uma companhia para mim!

O cuidado como essência do humano somente é genuíno quando promove a aproximação entre os indivíduos, de tal maneira que cuidar da pessoa idosa inclua e ultrapasse ações técnicas por meio do compartilhamento de afetos, sentimentos de confiança, conforto e satisfação da necessidade do outro. As experiências gratificantes 
dizem respeito à satisfação pessoal de assumir o cuidado com atitudes e sentimentos de devoção, amor, afeto ${ }^{19,24,25}$. Essas atitudes se referem a laços afetivos sólidos e, frequentemente, se associam a uma rede de apoio que dá suporte seja na alternância no cuidado, no amparo afetivo ao familiar ou na divisão de tarefas ${ }^{26,27}$. Alguns cuidadores entrevistados mostraram que, apesar de terem suas escolhas pessoais tolhidas ou postergadas, adaptam-se às novas atribuições, entendendo-as como existencialmente significativas.

Em resumo, para muitos filhas e filhos entrevistados, o exercício do cuidado e o respeito aos mais velhos são considerados obrigação amorosa. Embora enunciem muitas razões pelas quais assistem e se preocupam com o bem estar dos pais, os sentimentos de gratidão são os mais fortes. Alguns enunciaram que o cuidado é também um investimento no futuro, quando esperam receber cuidados de suas respectivas famílias ${ }^{5}$. Embora pouco relatado, alguns filhos comentaram que a institucionalização do idoso não é a melhor forma de se viver na velhice, e que o lugar de seus entes queridos é na família. Esse aspecto cultural das subjetividades difere de outros países, onde o cuidado aos idosos, centralizado no asilo, é visto como natural ${ }^{5}$. Também os idosos em condições cognitivas de responder, quando perguntados, disseram preferir estar com suas famílias do que em residências geriátricas.

\section{Renúncia a projetos de vida atuais e futuros}

Aqui são agrupados os conteúdos que incorporam vivências de abandono, irritação, queixas por excesso de responsabilidade, falta de apoio nas rotinas de cuidado, e exaustão de forças físicas e psíquicas por parte dos cuidadores. Como afirma DPFS, 42 anos, residente em Araranguá, filha que cuida da mãe há cinco anos:

A gente tem desavença familiar e ele [irmão] se nega a ajudar e isso dá uma discussão, pesa tudo junto e têm dias que é bem difícil, eu tenho que me equilibrar, se não, vou para o fundo do poço e tem que ser assim e infelizmente não vai mudar.

Em famílias onde os conflitos fazem parte da cultura relacional, o peso do cuidado é geralmente colocado sobre os ombros de apenas uma pessoa e vivenciado com sentimentos de impaciência, injustiça, raiva e estresse. Apareceu em vários relatos o sentimento de injustiça por parte do cuidador. Ele foi destacado como fonte de grande sofrimento e costuma se apresentar como ressentimento pela não repartição de responsabilidades para com o idoso dependente ${ }^{19}$.
Nesses casos, ocorre uma espécie de troco dado pela vida em famílias marcadas por laços frouxos de afetividade. Nas entrevistas há relatos sobre filhos, maridos e outros parentes que, mesmo podendo, não compartilham gastos, e pouco ou nada buscam visitar ou ter notícias da pessoa dependente. Nessas situações, novas e velhas feridas familiares ganham vivacidade e tornam a situação da dependência ainda mais árdua e difícil $^{19,24,25}$. Esse problema não é restrito ao Brasil. Investigação realizada no Canadá encontrou que maridos, esposas e filhos que não escolhem cuidar da pessoa dependente em casa apresentam pior bem-estar psicológico quando comparados com familiares que assumiram cuidar ${ }^{28}$.

A renúncia pessoal exigida pela condição de dependência do idoso, em muitos casos, implica num cuidado descuidado de si por parte do cuidador, como se observa no relato de CMSDM, 37 anos, residente em Belo Horizonte, filha que cuida da mãe há três anos:

Não tem muito essa coisa de cuidar [de si], é muita luta! Chega de noite eu quero é dormir mesmo, coloco meus meninos para dormir e vou dormir também [...] eu nem paro para pensar porque se for pensar nos problemas você não dorme. É um dia de cada vez. Hoje ela está com mais dificuldade, então eu fico por conta dela. Hoje ela está mais tranquila, eu vou fazendo minhas coisas.

Esse depoimento revela uma mulher multitarefas - a que cuida da família e da pessoa idosa - que foi recorrente entre os entrevistados. Mais um motivo para o descuido pessoal, porque a maioria das cuidadoras não consegue equilibrar o cuidado por si mesma e pelo outro, e acabam dando preferência ao outro ${ }^{15,19}$. A negligência pessoal, em favor do atendimento às demandas da família foi vista também na Espanha onde existe uma lei que proporciona vários tipos de ajuda. Apesar disso, muitos familiares expressaram não ter tempo para se dedicar a outras atividades que desejariam ${ }^{25}$.

A própria experiência de uma vida que pas$s a$, construída cronologicamente, faz com que os cuidadores familiares sintam que perderam a capacidade de controlar seu tempo ${ }^{26}$.

A pouca resistência emocional do cuidador familiar pode aumentar a ansiedade pela carga que significa atender às necessidades básicas de vida diária, manter horas de vigilância e se recompor pessoalmente ${ }^{2,27}$. Por isso, é preciso ter um olhar atento voltado para o sofrimento de quem cuida ${ }^{14}$. Em vários países há programas específicos de suporte psicológico aos cuidadores familiares ajudando-os a lidar com a tristeza, a 
dor, a solidão e o desamparo ${ }^{15,16,24,25,29}$. No Brasil, ainda são muito pontuais as iniciativas e não há uma política pública nesse sentido.

A situação de cuidado da pessoa idosa afeta, sobretudo, a socialização e a interação com ou$\operatorname{tros}^{2,19}$. A restrição ao lar é um ajuste prático, com repercussões subjetivas, comentado por quase todos os participantes, entre eles MMRS, 60 anos de Fortaleza, filha que cuida dos pais há três anos e AAS, 71 anos, residente em Teresina, que cuida do idoso há quatro anos:

Eu me encontro com 60 anos e não sou mais uma jovenzinha, então o cansaço, o estresse bate, eu cuido de duas pessoas com vontades diferentes, tenho minha família, meu marido, então a gente renuncia nossa vida em tudo, não pode programar nada, vivo em função deles, não tenho lazer, não tenho nada, vivo para eles.

Esses dias eu não fui para igreja porque estava sem condição mesmo, cansada. Eu estava tão cansada de passar o dia lutando com ele.

Mesmo quando há alternância no cuidado, o gerenciamento e a responsabilidade recaem muitas vezes sobre um único membro familiar. O esgotamento físico e psíquico sentido como verdadeira luta, leva o cuidador familiar a sentir que a cada dia recomeça uma tarefa pesada e repetitiva que o consome $e^{18,25,30,31}$.

As razões que levam os cuidadores a se retraírem no domicílio são de caráter prático, ligadas à falta de mobilidade, acesso, materiais de apoio ao cuidado e equipamentos sociais. Sentir-se sozinho se relaciona ainda à invisibilidade que envolve o cuidar ${ }^{24,29}$. Em essência, a solidão pode ser comparada a uma espécie de luto em que a pessoa perde o mundo em que vive, tal como o conhecia e desejava ${ }^{29,32}$.

Em diversos relatos encontra-se uma atitude de desistência de sair de casa por parte do cuidador e do idoso dependente, o que significa isolar-se em um mundo repetitivo com pouco estímulo. As questões financeiras pesam muito nesse sentido. Diversas pessoas entrevistadas têm baixa renda, não possuem cadeira de rodas para os idosos que dela necessitam e residem em domicílios que dificultam a locomoção. Consequentemente, essa é mais uma importante razão para se criarem iniciativas de apoio a cuidadores familiares, especialmente, os mais pobres ${ }^{18}$.

A renúncia ao mundo do trabalho, voluntária ou imposta, é uma das principais restrições e frustrações apontadas por EM, 48 anos, filha, cuida da mãe há quatro anos em Araranguá:

Quando ela estiver bem boa, eu vou começar a procurar emprego. Agora não tem como, porque eu tenho que levar no médico, tenho que fazer compras, pagar, então ela depende de mim. Eu preciso arranjar um emprego que eu consiga conciliar com o cuidado dela, algo que seja aqui perto. Eu quero trabalhar. Tenho as minhas coisas e hoje eu estou dependendo dela.

No relato acima, a filha coloca em xeque o cuidado sem nenhuma compensação financeira, o que, de um lado, evidencia o empobrecimento do cuidador e, de outro, aumenta a tensão intrafamiliar e pessoal, o que pode comprometer a qualidade da assistência. Esse é um tema recorrente na literatura que relaciona cuidador, idoso e família. Em vários países, quem cuida recebe um subsídio do Estado ${ }^{18,32}$.

Paralelamente à perda ou renúncia do posto no mercado formal de trabalho, vários cuidadores ressaltam a desvalorização social da atividade de cuidar, fortemente associada ao trabalho doméstico e não considerada trabalho de verdade. $\mathrm{O}$ que podemos perceber no relato de MLV, 45 anos, residente em Brasília, filho, cuida do pai há seis anos:

Eu fico irritado com os vizinhos e conhecidos que me indagam por que não estou trabalhando. Ás vezes eu realizo alguns serviços de pintura na vizinhança, mas ninguém entende que eu fico triste por não poder voltar ao mercado de trabalho e que eu faço o possivel e impossível para que meu pai seja atendido em todas as suas necessidades.

A percepção social do trabalho executado pelo cuidador tem dois lados de invisibilidade e minusvalia: de um, é exigido que ele tenha responsabilidade ética e moral no cumprimento do silencioso contrato familiar; de outro, socialmente, sua atividade não é reconhecida como trabalho. Assim, além da sobrecarga emocional, física e psíquica, o cuidador frequentemente é visto como ocioso, que se esquiva do trabalho de verdade, particularmente se for homem ${ }^{28}$. Esse problema é mencionado também na literatura internacional. Em Portugal, estudos mostram que os cuidadores discorrem que parentes e amigos ao visitar a pessoa dependente só têm acesso a uma realidade aparente: seus esforços de uma pesada rotina permanecem ocultos ${ }^{25}$.

Diversos são os casos de idosos acamados contados por cuidadores impacientes, cansados e estressados: eles gemem, gritam, agitam-se e não dormem à noite. Em várias situações, os cuidadores confessam que não conseguem controlar a irritabilidade e a impotência frente aos quadros de comprometimentos cognitivos e comportamentais $^{33}$.É o caso de CRS de Fortaleza, 50 anos, filha cuida da mãe com Alzheimer há nove anos: 
eu brigo, fico estressada, cansada, era para eu ter mais paciência, mas eu vou falhando, o pior é a alteração de humor dela!

$\mathrm{Na}$ maioria dos casos, apesar de todas as dificuldades, a pesquisa mostra que os cuidadores buscam um ajuste emocional, frente ao dilema existencial de cuidar ou reagir às provocações voluntárias ou involuntárias dos idosos: tentam compreender o sofrimento de quem cuidam e neutralizar sentimentos de irritação e culpa.

Estudo brasileiro com cuidadoras familiares ${ }^{32}$ sinalizou que elas temem ser julgadas e julgam a si mesmas quando irritadas e tensas, no entanto, objetivamente, uma carga de trabalho intensa e sem descanso, impacta sua qualidade de vida.

Estudiosos do mundo inteiro estão discutindo a situação desse trabalhador invisível que é o cuidador familiar ${ }^{29}$. A maioria dos trabalhos, nesse sentido, advoga que o Estado e a Sociedade - e não apenas a família - precisam se mobilizar e produzir uma política que beneficie quem é cuidado e seu cuidador ${ }^{30,31,34}$.

\section{Considerações finais}

O texto buscou descrever e interpretar a experiência de um grupo de cuidadores familiares de idosos dependentes, a maioria mulheres. Alguns pontos merecem destaque:

1. A descoberta de que uma pessoa idosa já não tem a autonomia necessária para as atividades da vida diária e instrumentais pode provocar um impacto no seu núcleo familiar.

2. Os cuidadores familiares, pela dificuldade de dividir com outros parentes a atribuição de assistir os idosos, se privam de projetos profissionais e existenciais e precisam ser reconhecidos e apoiados.
3. O envolvimento afetivo dos familiares com o cuidado pode ser marcado pelos mais diferentes sentimentos: dedicação, compaixão e busca de apoio; isolamento, simbiose e dependência emocional; angústia, desespero e sensação de impotência; impaciência e raiva. Frequentemente, essa variedade de sentimentos se mistura.

4. Nos mais diferentes cenários afetivos, o lar é o espaço do cuidado, da solidariedade ou da tragédia e da culpa. A maioria das pessoas idosas no Brasil contemporâneo vive com sua família e quando dependente é cuidada por ela, não tendo apoio e proteção do Estado.

5. A reordenação dos projetos de vida dos que assumem ser cuidadores geralmente inclui restrições e renúncias. Restrições para conciliar o cuidado com o trabalho remunerado e com outras atividades da vida diária. Renúncia a uma vida social ativa somada à desvalorização social do seu trabalho.

6. Vale lembrar que ter uma família extensa não é pressuposto de que o cuidador terá ajuda para cumprir sua tarefa, ou para repor suas energias. Quase sempre apenas uma pessoa assume o ônus do cuidado.

7. As situações de maior sofrimento para os cuidadores ocorrem quando há conflitos familiares antigos e mal resolvidos. Em geral, nesses casos, afloram ressentimentos, disputas pelo direito de cuidar ou de controlar a situação, problemas financeiros e sensação de que a carga de assistir recai injustamente sobre somente uma pessoa.

8. Compreender as vivências subjetivas dos cuidadores familiares de idosos dependentes é muito importante para que lhes seja oferecido apoio adequado em intervenções bem fundamentadas. Mas, sobretudo, para subsidiar uma política pública específica que, de fato, leve em conta suas experiências concretas e vivências socioafetivas. 


\section{Colaboradores}

DMD Gutierrez, GS Sousa, AEB Figueiredo, MNS Ribeiro, CX Diniz e GASS Nobre participaram da concepção do tema do artigo, coleta dos dados, análise e interpretação dos dados e elaboração do texto. Todos os autores realizaram revisão crítica e aprovação da versão final do manuscrito.

\section{Referências}

1. Organização Mundial de Saúde (OMS). Relatório mundial de envelhecimento e saúde. Geneva: OMS; 2015.

2. Floriano LA, Azevedo RDS, Reiners AAO, Sudré MRS. Care performed by family caregivers to dependent elderly, at home, within the context of the family health strategy. Texto Contexto Enferm 2012: 21(3):543-548.

3. Faller JW, Zilly A, Alvarez AM, Marcon SS. Filial care and the relationship with the elderly in families of different nationalities. Rev. Bras. Enferm. 2017; 70(1):2230.

4. Kuluski K, Peckham A, Gill A, Arneja J, MortonChang F, Parsons J, Sheridan, N. "You've got to look after yourself, to be able to look after them" a qualitative study of the unmet needs of caregivers of community based primary health care patients. $B M C$ geriatrics 2018; 18(1):275.

5. Greenwood N, Smith R. Motivations for being informal carers of people living with dementia: a systematic review of qualitative literature. BMC Geriatrics 2019; 19(1): e169.

6. González-Rey F. O social na psicologia e a psicologia social. Petrópolis: Vozes; 2004.

7. Minayo MCS, Figueiredo AEB. Manual de pesquisa Estudo situacional dos idosos dependentes que residem com suas famílias visando a subsidiar uma política de atenção e de apoio aos cuidadores. Rio de Janeiro: Fiocruz; 2018.

8. Heidegger M. Ser e tempo. 3a ed. Petrópolis: Vozes; 2008. (Parte I e II).

9. Andersen HE, Hoeck B, Nielsen DS, Ryg J, Delmar CA. Phenomenological-hermeneutic study exploring caring responsibility for a chronically ill, older parent with frailty. Nursing Open 2020; 7(4):951-960.

10. Gadamer H-G. Verdade e Método. Traços fundamentais de uma hermenêutica filosófica. Petrópolis: Vozes; 1999.

11. Jung CG. Fondamenti psicologici nella credenza degli spiriti. In: Jung CG. Opere. Torino: Boringhieri; 1976. (vol. 8).

12. Mauss M. A expressão obrigatória dos sentimentos. In: Figueira S, organizador. Psicanálise e ciências sociais. Rio de Janeiro: Francisco Alves; 1980. p. 56-63.

13. Pérez-Cruz M, Parra-Anguita L, López-Martínez C, Moreno-Cámara S, del-Pino-Casado R. Burden and Anxiety in Family Caregivers in the Hospital That Debut in Caregiving. Int J Environ Res Public Health 2019: 16(20):3977.

14. Santos-Orlandi AAD, Brigola AG, Ottaviani AC, Luchesi BM, Souza EN, Moura FG, Zacarin JF, Terassi M, Oliveira NA, Pavarini SCI. Elderly caregivers of the elderly: frailty, loneliness and depressive symptoms. Rev. Bras. Enferm 2019: 72:88-96.

15. Liu H, Lou VW. Transitioning into spousal caregiving: contribution of caregiving intensity and caregivers' multiple chronic conditions to functional health. Age and Ageing 2019; 48(1):108-114.

16. Bourdieu P. A dominação masculina. $2^{\text {a }}$ ed. Rio de Janeiro: Bertrand do Brasil; 2002.

17. Baker KL, Robertson N, Connelly D. Men caring for wives or partners with dementia: Masculinity, strain and gain. Aging \& Mental Health 2010; 14(3):319-327. 
18. Shahly V, Chatterji S, Gruber MJ, Al-Hamzawi A, Alonso J, Andrade LH, Angermeyer MC, Bruffaerts R, Bunting B, Caldas-de-Almeida JM, Girolamo G, Jonge P, Florescu S, Gureje O, Haro JM, Hinkov HR, Hu C, Karam EG, Lépine J-P, Levinson D, MedinaMora ME, Posada-Villa J, Sampson NA, Trivedi JK, Viana MC, Kessler RC. Cross-national differences in the prevalence and correlates of burden among older family caregivers in the World Health Organization World Mental Health (WMH) Surveys. Psychol Med 2013; 43(4):865-879.

19. Couto, AMD, Caldas CP, Castro, EABD. Family caregiver of older adults and Cultural Care in Nursing care. Rev. Bras. Enferm. 2018; 71(3):959-966.

20. Hogan R. Human sexuality - a nursing perspective. $2^{\text {a }}$ ed. Connecticut: Appleton Century Crofts; 1985.

21. Santos WJD, Giacomin KC, Firmo JOA. Alteridade do corpo do velho: estranhamento e dor na Saúde Coletiva. Cien Saude Colet 2019; 24(11):4275-4284.

22. Bleger J. Simbiosis y ambigüedad: estudio psicoanaitico. Buenos Aires: Paidós; 2001.

23. Bornstein RF. Illuminating a neglected clinical issue: Societal costs of interpersonal dependency and dependent personality disorder. Journal of clinical psychology 2012; 68(7):766-781.

24. Mendez-Luck CA, Anthony KP, Guerrero LR. Burden and bad days among mexican-origin women caregivers. J Gerontol B Psychol Sci Soc Sci 2019; 75(8):17191730.

25. Moreno-Cámara S, Palomino-Moral PA, Moral-Fernández L, Frías-Osuna A, del-Pino-Casado R. Problemas en el proceso de adaptación a los câmbios en personas cuidadoras familiares de mayores con demencia. Gac Sanit 2016; 30(3):201-207

26. Oxfam. Relatório sobre nós e a desigualdade "tempo de cuidar". Davos: Fórum Econômico Mundial; 2020.

27. Anjos KF, Boery RNSO, Pereira R. Quality of life of relative caregivers of elderly dependents at home. Texto Contexto - Enferm 2014; 23(3):600-608.

28. Rosas C, Neri AL. Quality of life, burden, family emotional support: a model for older adults who are caregivers. Rev. Bras. Enferm 2019; 72(s/n):169-176.
29. Givens JL, Mezzacappa C, Heeren T, Yaffe K, Fredman L. Depressive symptoms among dementia caregivers: role of mediating factors. The American Journal of Geriatric Psychiatry 2014; 22(5):481-488.

30. Koumoutzis A, Cichy KE, Dellmann-Jenkins M, Blankemeyer M. Age Differences and Similarities in Associated Stressors and Outcomes Among Young, Midlife, and Older Adult Family Caregivers. Int J Aging Hum Dev 2020; 91415020905265.

31. Li L, Lee Y. Caregiving Choice and Caregiver-Receiver Relation: Effects on Psychological Well-being of Family Caregivers in Canada. Can J Aging 2020; 1-13.

32. Araújo MGDO, Dutra MOM, Freitas CCSL, Guedes TG, Souza FSD, Baptista RS. Caring for the carer: quality of life and burden of female caregivers. Rev Bras Enferm 2019; 72(3):728-736.

33. Ris I, Schnepp W, Mahrer Imhof R. An integrative review on family caregivers' involvement in care of home-dwelling elderly. Health Soc Care Community 2019; 27(3):e95-e111.

34. Minayo MCS. O imperativo de cuidar da pessoa idosa dependente. Cien Saude Colet 2019; 24(1):247-252.

Artigo apresentado em 02/06/2020

Aprovado em 11/08/2020

Versão final apresentada em 13/08/2020

Editores chefes: Maria Cecília de Souza Minayo, Romeu Gomes, Antônio Augusto Moura da Silva. Editora Associada da área de Saúde do Idoso: Joselia Oliveira Araújo Firmo 